\title{
The $3^{\prime}$-end-processing factor CPSF is required for the splicing of single-intron pre-mRNAs in vivo
}

\author{
YONGZHONG LI, ${ }^{1,3 *}$ ZHONG-YING CHEN, ${ }^{1,4 *}$ WEIRONG WANG,${ }^{5 *}$ CARL C. BAKER, ${ }^{2}$ \\ and ROBERT M. KRUG ${ }^{1}$ \\ ${ }^{1}$ Institute for Cellular and Molecular Biology, Section of Molecular Genetics and Microbiology, \\ University of Texas at Austin, Austin, Texas 78712, USA \\ ${ }^{2}$ Basic Research Laboratory, Center for Cancer Research, National Cancer Institute, Bethesda, Maryland 20892, USA
}

\begin{abstract}
We describe a new approach to elucidate the role of $3^{\prime}$-end processing in pre-mRNA splicing in vivo using the influenza virus NS1A protein. The effector domain of the NS1A protein, which inhibits the function of the CPSF and PABII factors of the cellular $3^{\prime}$-end-processing machinery, is sufficient for the inhibition of not only $3^{\prime}$-end formation but also the splicing of single-intron pre-mRNAs in vivo. We demonstrate that inhibition of the splicing of single-intron pre-mRNAs results from inhibition of $3^{\prime}$-end processing, thereby establishing that $3^{\prime}$-end processing is required for the splicing of a $3^{\prime}$ terminal intron in vivo. Because the NS1A protein causes a global suppression of $3^{\prime}$-end processing in trans, we avoid the ambiguities caused by the activation of cryptic poly(A) sites that occurs when mutations are introduced into the AAUAAA sequence in the pre-mRNA. In addition, this strategy enabled us to establish that the function of a particular $3^{\prime}$-end-processing factor, namely CPSF, is required for the splicing of single-intron pre-mRNAs in vivo: splicing is inhibited only when the effector domain of the NS1A protein binds and inhibits the function of the $30-\mathrm{kDa}$ CPSF protein in $3^{\prime}$-end formation. In contrast, the $3^{\prime}$-end processing factor PABII is not required for splicing. We discuss the implications of these results for cellular and influenza viral mRNA splicing.
\end{abstract}

Keywords: 3 '-end processing; CPSF; influenza virus NS1A protein; PABII; pre-mRNA splicing

\section{INTRODUCTION}

Most eukaryotic pre-mRNAs undergo a common set of processing steps in the nucleus, including splicing to remove introns and $3^{\prime}$-end processing to produce $3^{\prime}$ poly $(A)$ tails. The production of $3^{\prime}$ poly $(A)$ tails occurs in two coupled steps: endonucleolytic cleavage of the pre-mRNA followed by the addition of poly $(A)$ to the upstream cleavage product (reviewed in Colgan \& Manley, 1997; Wahle \& Kuhn, 1997). Two sequences in the pre-mRNA are recognized: a conserved AAUAAA hexamer that is located $10-30 \mathrm{nt}$ upstream of the cleavage site, and a U- or G/U-rich element downstream of the

Reprint requests to: Robert M. Krug, Institute for Cellular and Molecular Biology, University of Texas at Austin, Austin, Texas 78712, USA; e-mail: rkrug@icmb.utexas.edu.

*These authors made equal contributions to this research.

${ }^{3}$ Present address: PTC Therapeutics Inc.,100 Corporate Court, South Plainfield, New Jersey 07080, USA.

${ }^{4}$ Present address: Johnson \& Johnson, Consumer Products Worldwide, 199 Grandview Road, Skillman, New Jersey 08558, USA.

${ }^{5}$ Present address: Department of Molecular Genetics and Microbiology, University of Medicine and Dentistry of New Jersey-Robert Wood Johnson Medical School, Piscataway, New Jersey 08855, USA. cleavage site. Six cellular factors, several of which are comprised of several protein subunits, are required for efficient 3 '-end formation. Two of these factors recognize, and bind to, the conserved sequences in premRNAs. CPSF (cleavage and polyadenylation specificity factor) binds to the AAUAAA hexamer via its $160-\mathrm{kDa}$ subunit and possibly its 30-kDa subunit (Keller et al., 1991; Murthy \& Manley, 1992; Jenny et al., 1994; Barabino et al., 1997). CstF (cleavage stimulation factor) binds to the $U$ - or $\mathrm{G} / \mathrm{U}$-rich element downstream of the cleavage site, and stabilizes the binding of CPSF to the AAUAAA sequence of the pre-mRNA (reviewed in Colgan \& Manley, 1997; Wahle \& Kuhn, 1997).

The exon definition model for pre-mRNA splicing predicts that $3^{\prime}$-end-processing factors play an important role in splicing (Niwa et al., 1990; Niwa \& Berget, 1991; Berget, 1995). According to this model, splicing requires interactions between the splicing factors that bind to the two ends of each exon, that is, between the splicing factors at the $3^{\prime}$ splice site of the upstream intron and those at the $5^{\prime}$ splice site of the downstream intron. As a result of these interactions, neighboring exons are juxtaposed, leading to the excision of the 
intervening intron. Likewise, because a $3^{\prime}$ terminal exon begins with a $3^{\prime}$ splice site and ends with the site for $3^{\prime}$-end processing, the recognition of this terminal exon during splicing would be mediated by interactions between $3^{\prime}$-splice-site factors and $3^{\prime}$-end-processing factors. Consequently, mutation of the $3^{\prime}$ poly $(A)$ site should inhibit the splicing of the $3^{\prime}$ proximal intron, but not of upstream introns. In fact, such a result has been obtained in in vitro experiments using nuclear extracts that are active in both splicing and $3^{\prime}$-end processing (Niwa \& Berget, 1991; Berget, 1995; Vagner et al., 2000). In addition, the interaction was shown to be bidirectional: mutation of the $3^{\prime}$ splice sites of a pre-mRNA inhibits their $3^{\prime}$-end processing in vitro (Niwa et al., 1990). However, the results of in vivo experiments have been less definitive. As is the case in vitro, mutation of $3^{\prime}$ splice sites inhibits $3^{\prime}$-end processing of a mammalian pre-mRNA in vivo (Nesic \& Maquat, 1994; Dye \& Proudfoot, 1999). In contrast, although the strength of a $3^{\prime}$ poly $(A)$ site has been shown to influence the efficiency of splicing of a $3^{\prime}$ terminal intron in vivo (Scott \& Imperiale, 1996), it has not been possible to establish that $3^{\prime}$-end processing is required for splicing of a $3^{\prime}$ terminal intron in vivo because cryptic poly $(A)$ sites are invariably activated in the presence of an intron. In fact, mutation of the $3^{\prime}$ poly $(A)$ site that is normally used for $3^{\prime}$-end processing of a mammalian pre-mRNA in vivo does not inhibit splicing of the $3^{\prime}$ terminal intron because of this activation of cryptic poly (A) sites (Nesic et al., 1995).

Transcription and pre-mRNA processing are linked in vivo (reviewed in Bentley, 1999; Minvielle-Sebastia \& Keller, 1999; Hirose \& Manley, 2000). CPSF and CstF, the two 3 '-end-processing factors that recognize conserved sequences in pre-mRNAs, associate with elongating RNA polymerase II via the hyperphosphorylated carboxy terminal domain (CTD) of the large subunit of the polymerase. CPSF, which is recruited by the TFIID transcription factor, is transferred to the CTD of RNA polymerase II and apparently remains associated with the elongating polymerase during transcription (Dantonel et al., 1997). When the polymerase reaches the AAUAAA signal for 3 '-end processing, cleavage is postulated to occur via two possible mechanisms. In one model, CPSF and CstF dissociate from the CTD and bind to the AAUAAA sequence and the downstream Uor G/U-rich element, respectively, in the pre-mRNA, where they function in $3^{\prime}$ cleavage of the pre-mRNA (Dantonel et al., 1997; McCracken et al., 1997). In the other model, CPSF and CstF remain associated with the CTD because the CTD itself may be a required factor for 3'-end cleavage (Hirose \& Manley, 1998). The CTD of RNA polymerase II also appears to play a role in pre-mRNA splicing. Overexpression of the CTD in vivo inhibits splicing (Du \& Warren, 1997), and deletion of the CTD inhibits splicing and the targeting of the splicing machinery to transcription sites in the nu- cleus (McCracken et al., 1997; Misteli \& Spector, 1999), strongly suggesting that the CTD binds essential splicing factors. Proteins that could potentially function in splicing, for example, proteins with serine/arginine-rich domains similar to known SR splicing factors, are physically associated with the CTD (reviewed in Bentley, 1999; Hirose \& Manley, 2000). In fact, it has been shown that RNA polymerase II that contains a phosphorylated CTD participates directly in the splicing reaction by stimulating an early step in spliceosome formation (Hirose et al., 1999). The complex that contains RNA polymerase II and multiple RNA processing factors has been denoted as the "pol II transcriptosome" (Hirose \& Manley, 2000).

In the present study, we use the NS1 protein of influenza A virus (NS1A protein) to elucidate the role of $3^{\prime}$-end processing in the splicing of the $3^{\prime}$ terminal intron of mammalian pre-mRNAs in vivo. This viral protein contains two functional domains: an RNA-binding/ dimerization domain at the amino terminus and an effector domain in the carboxy half (Qian et al., 1994; Wang \& Krug, 1996). The effector domain interacts with two essential components of the machinery for the 3 'end processing of cellular pre-mRNAs: the 30-kDa subunit of CPSF and poly (A)-binding protein II (PABII) (Nemeroff et al., 1998; Chen et al., 1999). The consequent inhibition of CPSF and PABIl function efficiently blocks the $3^{\prime}$-end processing of cellular pre-mRNAs in both transfected cells and influenza virus-infected cells, and, as a result, cellular mRNAs are not exported from the nucleus (Nemeroff et al., 1998; Chen et al., 1999). In addition, as established by transfection experiments, the NS1A protein inhibits the in vivo splicing of premRNAs containing a single intron (Fortes et al., 1994; Lu et al., 1994).

We demonstrate that inhibition of the splicing of singleintron pre-mRNAs results from inhibition of $3^{\prime}$-end processing, thereby establishing that $3^{\prime}$-end processing is required for the splicing of $3^{\prime}$ terminal introns in vivo. By employing the NS1A protein that causes a global suppression of $3^{\prime}$-end processing in trans, we avoid the ambiguities caused by the activation of $\operatorname{cryptic} \operatorname{poly}(\mathrm{A})$ sites that occurs when mutations are introduced into the AAUAAA sequence in the pre-mRNA. In addition, this strategy enabled us to establish that the function of a particular $3^{\prime}$-end processing factor, namely CPSF, is required for the splicing of single intron pre-mRNAs in vivo.

\section{RESULTS}

\section{The effector domain of the NS1A protein is sufficient for the inhibition of $3^{\prime}$-end processing of cellular pre-mRNAs in vivo}

Previous studies have established that the effector domain of the NS1A protein is required for the inhibition of 
$3^{\prime}$-end processing of cellular pre-mRNAs (Nemeroff et al., 1998; Chen et al., 1999). Both the 30-kDa CPSF and PABII proteins bind to the effector domain, and deletion of the effector domain eliminates the ability of the NS1A protein to inhibit 3 '-end processing. A requirement for the RNA-binding domain, as well as the effector domain, in the inhibition of $3^{\prime}$-end processing was suggested by early mutagenesis experiments (Qian et al., 1994). Mutations in the RNA-binding domain as well as in the effector domain of the NS1A protein resulted in the loss of the ability of the NS1A protein to block the nuclear export of cellular mRNAs. This export block has been shown to result from the inhibition of 3 '-end processing of cellular pre-mRNAs (Nemeroff et al., 1998; Chen et al., 1999). However, the mutant NS1A proteins used in these studies are inactive in both RNA binding and dimerization (Lu et al., 1994; Qiu \& Krug, 1994; Qian et al., 1994; Nemeroff et al., 1995; Wang et al., 1999). Because the loss of dimerization is a profound change in the structure of the NS1A protein, the effector domain as well as the RNA-binding domain may be inactivated in such mutant proteins.

Consequently, to determine whether the RNA-binding domain is required for the inhibition of $3^{\prime}$-end processing, we used a different mutant NS1A protein that was designed based on the results obtained with the RNAbinding fragment of the protein (amino acids 1-73) (Wang et al., 1999). Only two amino acids, the arginine at position 38 and the lysine at position 41, in the RNAbinding fragment are required for efficient RNA binding, and these two amino acids are not required for dimerization. Accordingly, we replaced these two basic amino acids in the full-length NS1A protein with alanines, and determined whether the resulting mutant NS1A protein (38/41 mutant) dimerizes and possesses RNA-binding activity. As a control, we replaced the two arginines at positions 35 and 46 with alanines (35/46 mutant), because these replacements in the RNA-binding fragment result in a loss of dimerization as well as of RNAbinding activity (Wang et al., 1999).

The two mutant NS1A proteins were tested for their ability to form dimers using a glutathione Sepharose selection assay (Wang et al., 1999) (Fig. 1A). In vitrolabeled wild-type NS1A protein was combined with purified GST fusions of either wild-type NS1A protein, the $38 / 41$ mutant, or the 35/46 mutant. The mixtures were then selected on glutathione-Sepharose beads. The labeled wild-type NS1A protein forms a heterodimer with the GST-38/41 mutant protein (Fig. 1A, lane 3), approximately $80 \%$ as efficiently as the labeled wildtype NS1A protein forms a homodimer with the GSTwild-type protein (Fig. 1A, lane 2). In contrast, the 35/46 mutant protein is almost completely inactive in dimerization (Fig. 1A, lane 4).

The RNA-binding activity of the mutant NS1A proteins was assayed in gel-shift assays using U6 snRNA as the target (Lu et al., 1994; Qiu \& Krug, 1994; Wang

\section{A DimerizATION}

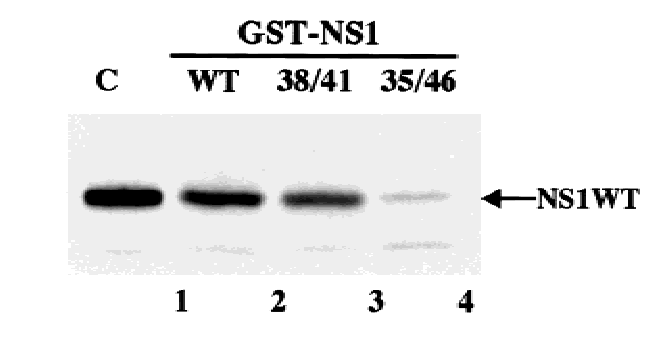

B RNA-BINDING

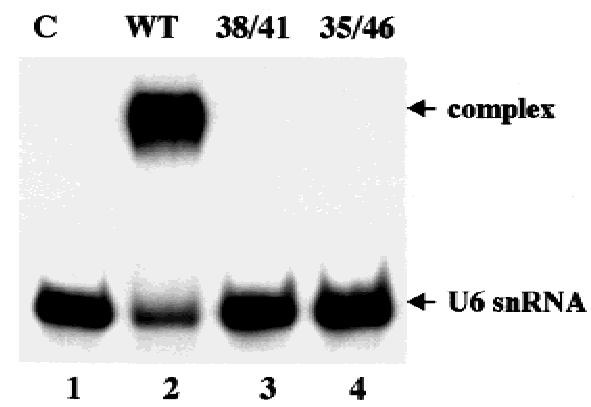

FIGURE 1. The 38/41 mutant NS1A protein dimerizes, but does not bind U6 snRNA. A: Dimerization assay. ${ }^{35}$ S-labeled, wild-type NS1A protein was incubated with glutathione-Sepharose 4B beads plus the GST fusion of either wild-type NS1A protein (lane 2), the 38/41 mutant protein (lane 3), or the 35/46 mutant protein (lane 4). After extensive washing, the ${ }^{35} \mathrm{~S}$-labeled, wild-type NS1 A protein that remained bound to the GST fusion protein on the beads was eluted and analyzed by electrophoresis on a 14\% SDS-PAGE gel. Lane 1: labeled wild-type NS1A protein before selection. B: RNA-binding assay. The indicated nonfusion wild-type or mutant NS1A protein $(500 \mathrm{nM})$ was incubated with U6 snRNA $(10,000 \mathrm{cpm}, 1 \mathrm{nM})$ on ice for $30 \mathrm{~min}$, and the protein-RNA complexes were separated from free RNA by nondenaturing gel electrophoresis.

et al., 1999) (Fig. 1B). Both the 38/41 and 35/46 mutant proteins are inactive in binding U6 snRNA (Fig. 1B, compare lanes 3 and 4 to lane 1), whereas under the same conditions, the wild-type NS1A protein shifts greater than $90 \%$ of the input U6 snRNA (Fig. 1B, lane 2). The same results were obtained using doublestranded RNA as the target (data not shown). We conclude that the $38 / 41$ mutant NS1A protein lacks detectable RNA-binding activity while retaining most (approximately $80 \%$ ) of wild-type dimerization activity.

To determine whether the effector domain of the NS1A protein alone is sufficient for the inhibition of $3^{\prime}$-end processing of cellular pre-mRNAs, 293 cells were cotransfected with two plasmids, one encoding a target pre-mRNA (a $\beta$-globin pre-mRNA) and one encoding an NS1A mRNA expressing either the wild-type NS1A protein or the $38 / 41$ mutant protein. Because these NS1A mRNAs have mutated $3^{\prime}$ splice sites, spliced NS2A mRNA is not produced (Qian et al., 1994). Similar amounts of the wild-type and mutant proteins were produced, as assayed by western analysis (data not 
shown). The relative amounts of the uncleaved premRNA and its $3^{\prime}$ cleaved product were determined by an RNase protection assay, using the probe shown in Figure $2 \mathrm{~A}$. In the absence of the NS1A protein, approximately $70 \%$ of the pre-mRNA is cleaved (Fig. 2B, lane 1). The wild-type NS1A protein almost completely inhibits cleavage: only approximately $5 \%$ of the premRNA is cleaved (Fig. 2B, lane 2). The $38 / 41$ mutant protein also inhibits cleavage, albeit not as effectively as the wild-type protein: approximately $20 \%$ of the premRNA is cleaved (Fig. 2B, lane 3 ). No significant effect of RNA stability was detected: the same relative amounts of uncleaved and cleaved RNAs were found after treatment of the cells for $3 \mathrm{~h}$ with actinomycin $\mathrm{D}(1 \mu \mathrm{g} / \mathrm{mL})$ to block further synthesis of $\beta$-globin pre-mRNA (data not shown). Consequently, the inhibitory activity of the $38 / 41$ mutant protein parallels its dimerization activity rather than its RNA-binding activity, indicating that the effector domain alone is sufficient for the inhibition of the $3^{\prime}$-end processing of cellular pre-mRNAs. In contrast to the $38 / 41$ mutant protein, NS1A proteins that have mutations in their RNA-binding domains that inactivate dimerization as well as RNA binding, for example, the 35/46 mutant protein (Wang et al., 1999), do not retain the ability to inhibit $3^{\prime}$-end processing (data not shown), indicating that dimerization is required for the preservation of this function of the effector domain in vivo.

\section{The effector domain of the NS1A protein is sufficient for the inhibition of the splicing of single-intron cellular pre-mRNAs in vivo}

The NS1A protein has been shown to inhibit not only $3^{\prime}$-end processing of cellular pre-mRNAs but also the in vivo splicing of pre-mRNAs that contain a single intron (Fortes et al., 1994; Lu et al., 1994). Two lines of evidence have implicated the RNA-binding domain of the NS1A protein in this function. First, mutations in either the effector domain or in the RNA-binding domain resulted in the loss of the ability of the NS1A protein to inhibit pre-mRNA splicing in vivo (Lu et al., 1994). However, as discussed above, the mutant NS1A proteins used in these studies were inactivated in both RNA-binding and dimerization (Lu et al., 1994; Qiu \& Krug, 1994; Qian et al., 1994; Nemeroff et al., 1995; Wang et al., 1999). Second, the RNA-binding domain of the NS1A protein binds to a specific stem-bulge in

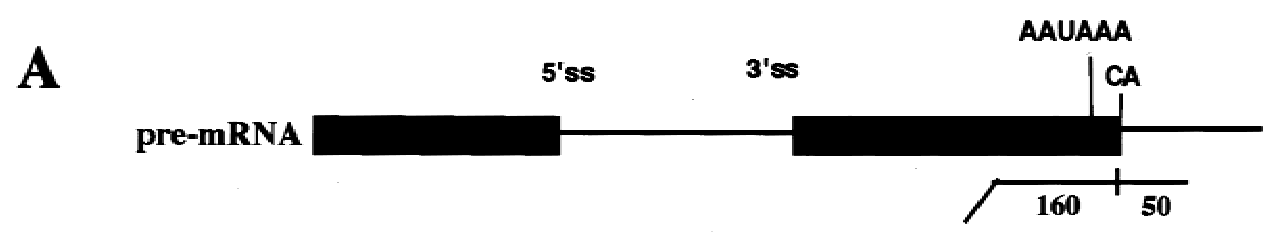

B
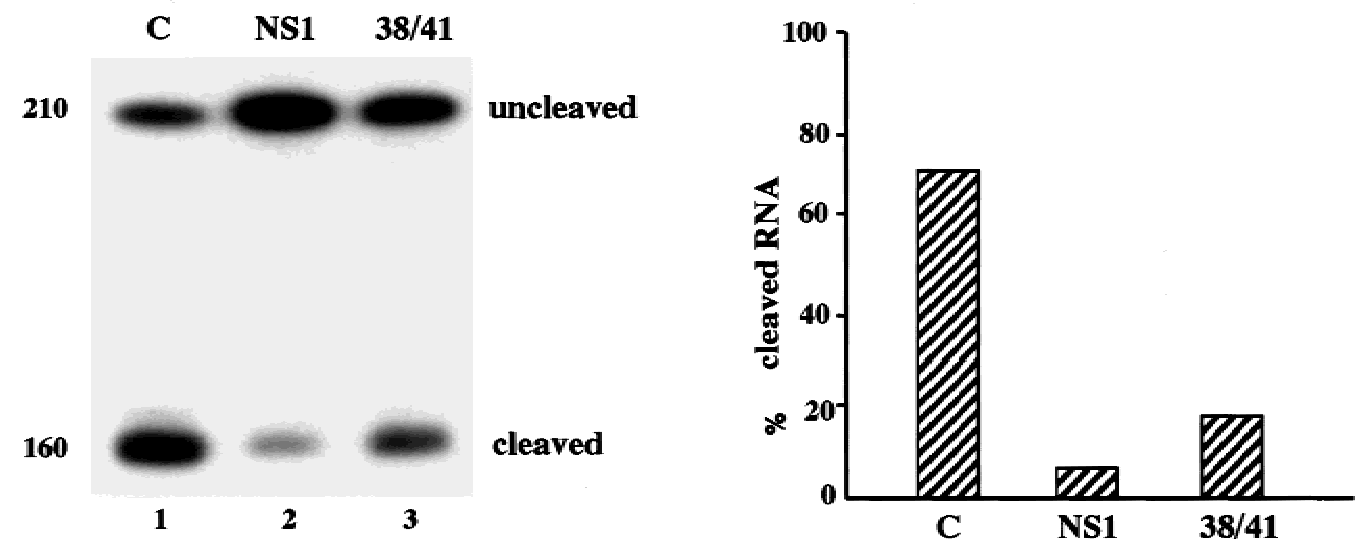

FIGURE 2. The 38/41 mutant NS1A protein inhibits $3^{\prime}$-end cleavage of a cellular pre-mRNA in vivo. A: Diagram of the uniformly-labeled RNA probe, and the predicted sizes of the protected RNA fragments. Because the RNA probe is complementary to the sequence that extends from $160 \mathrm{nt}$ upstream to $50 \mathrm{nt}$ downstream of the $3^{\prime}$ cleavage site, the uncleaved pre-mRNA should protect a 210-nt-long RNA fragment, whereas the cleaved RNA should protect a 160-nt-long RNA fragment. The RNA probe also contains $60 \mathrm{nt}$ at its $5^{\prime}$ end that is not complementary to a pre-mRNA sequence. B: $3^{\prime}$-end cleavage in vivo. We cotransfected 293 cells with a pBC12 plasmid encoding the $\beta$-globin pre-mRNA with a single-intron and a pBC12 plasmid encoding either the wild-type NS1A protein (lane 2) or the 38/41 mutant NS1A protein (lane 3). Control (C, lane 1): the pBC12 plasmid encodes an NS1A reading frame containing two stop codons. At $40 \mathrm{~h}$ posttransfection, the cellular RNA was extracted and subjected to a RNase protection assay. After RNase digestion, the protected fragments were resolved by denaturing gel electrophoresis (left panel). The sizes of the protected fragments are indicated. No residual RNA probe containing $270 \mathrm{nt}$ was detected. Right panel: quantitation of the percentage of the pre-mRNA that is cleaved in the three transfection experiments shown in the left panel. 
U6 snRNA (Qiu et al., 1995), and this binding is sufficient for the inhibition of the in vitro splicing of premRNAs (Lu et al., 1994; Qiu et al., 1995). However, both U6 snRNA binding and the inhibition of in vitro splicing require relatively high concentrations of the NS1A protein (approximately $1 \mu \mathrm{M}$ ) (Lu et al., 1994; Qiu et al., 1995). In addition, the pre-mRNAs used in these in vitro splicing experiments lack a 3 '-endprocessing site, the site that is targeted by the effector domain (Nemeroff et al., 1998; Chen et al., 1999; present study). Thus, the lack of a requirement for the NS1A effector domain in these in vitro splicing assays can be attributed to the absence of a $3^{\prime}$-end-processing site in the pre-mRNA substrates.
Based on these considerations, we tested the possibility that the effector domain of the NS1A protein alone is sufficient for the inhibition of splicing in vivo. We cotransfected 293 cells with two plasmids, one encoding a $\beta$-globin pre-mRNA containing a single intron and one encoding an unspliceable NS1A mRNA expressing either the wild-type NS1A protein or the 38/41 mutant protein. The relative amounts of the unspliced and spliced $\beta$-globin RNAs were determined by a RNase protection assay, using the probe shown in Figure 3A. In the absence of the NS1A protein, almost all the singleintron $\beta$-globin pre-mRNA is spliced (Fig. 3B, lane 1). In contrast, in the presence of the wild-type NS1A protein, only approximately $30 \%$ of the $\beta$-globin pre-mRNA is

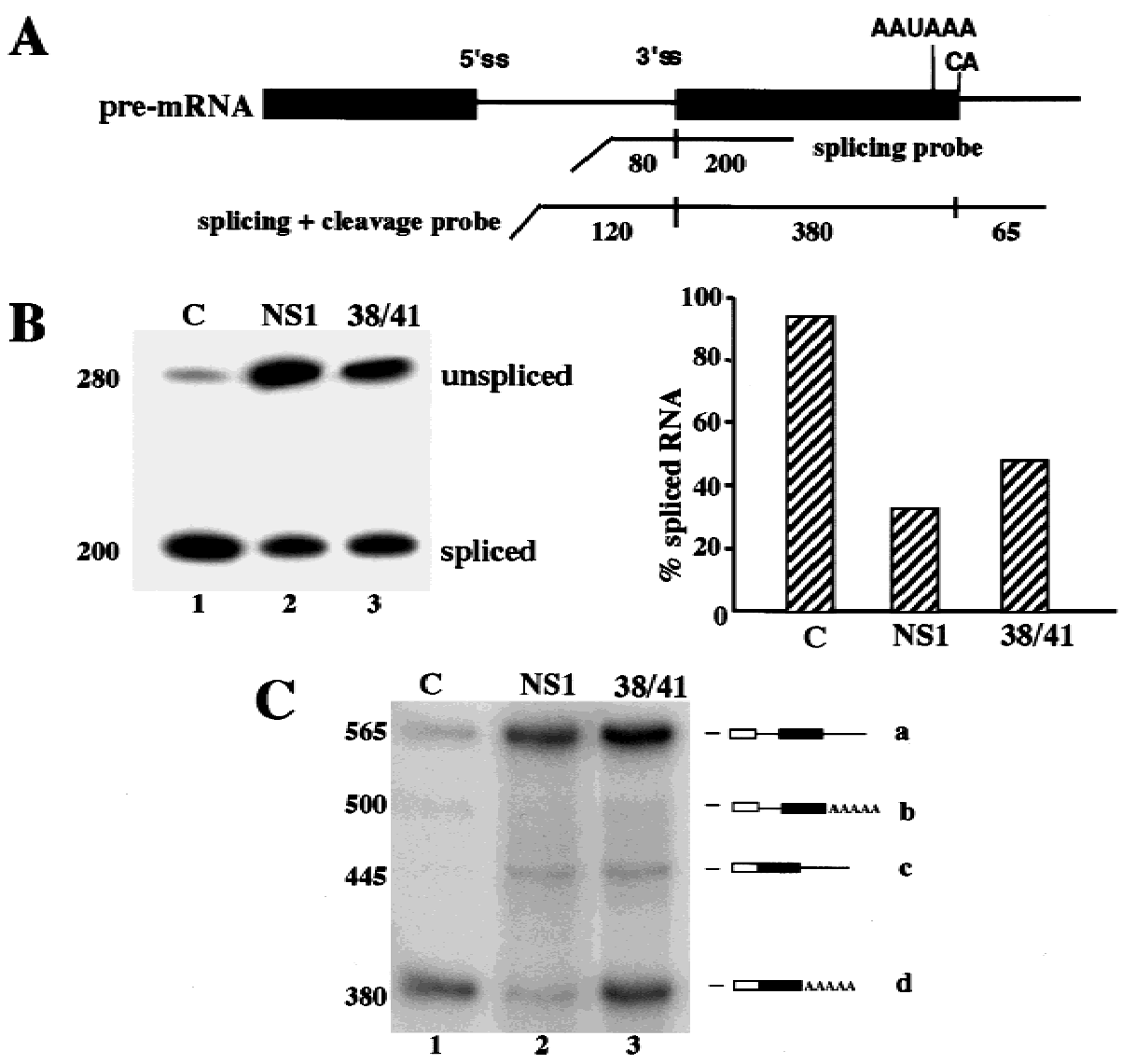

FIGURE 3. The $38 / 41$ mutant NS1A protein inhibits the splicing of a single-intron cellular pre-mRNA in vivo. A: Diagram of the uniformly labeled RNA probes, and the predicted sizes of the protected RNA fragments. Because the splicing probe is complementary to the sequence that extends from $80 \mathrm{nt}$ upstream to $200 \mathrm{nt}$ downstream of the $3^{\prime}$ ' splice site, the unspliced pre-mRNA should protect a 280-nt-long RNA fragment, whereas the spliced mRNA should protect a 200-nt-long RNA fragment. This RNA probe also contains 70 nt at its $5^{\prime}$ end that is not complementary to a pre-mRNA sequence. The RNA probe that was used to assay both splicing and cleavage is complementary to the sequence in the pre-mRNA that extends from 120 nt upstream of the $3^{\prime}$ splice site to 65 nt downstream of the $3^{\prime}$ cleavage site. Consequently, the sizes of the protected RNA fragments should be: uncleaved and unspliced pre-mRNA: $565 \mathrm{nt}$; cleaved and unspliced pre-mRNA: $500 \mathrm{nt}$; uncleaved and spliced pre-mRNA: $445 \mathrm{nt}$; cleaved and spliced mRNA: $380 \mathrm{nt}$. This RNA probe also contains 75 nt at its $5^{\prime}$ end that is not complementary to a pre-mRNA sequence. B: Splicing in vivo. Transfections were carried out as described in the legend of Figure 2, and the cellular RNA was subjected to a RNase protection assay using the splicing probe. After RNase digestion, the protected fragments were resolved by denaturing gel electrophoresis (left panel). The sizes of the protected fragments are indicated. No residual RNA probe containing $370 \mathrm{nt}$ was detected. Right panel: quantitation of the percentage of the pre-mRNA that is spliced in the three transfection experiments shown in the left panel. C: Transfections were carried out as described, and the splicing and $3^{\prime}$-end cleavage of the single-intron $\beta$-globin pre-mRNA were assayed at the same time using the splicing + cleavage probe shown in $\mathbf{A}$. The sizes of the protected fragments are indicated. Four RNA species were detected: a: uncleaved and unspliced pre-mRNA; b: cleaved and unspliced pre-mRNA; c: uncleaved and spliced pre-mRNA; d: cleaved and spliced pre-mRNA. No residual probe containing $640 \mathrm{nt}$ was detected. 
spliced (Fig. 3B, lane 2). The 38/41 mutant protein also inhibits splicing, though not as effectively as the wildtype NS1A protein: approximately $50 \%$ of the $\beta$-globin pre-mRNA is spliced (Fig. 3B, lane 3). Actinomycin D treatment of the transfected cells ruled out any significant effect of RNA stability (data not shown). In contrast to the $38 / 41$ mutant, the $35 / 46$ mutant protein, which is inactive in dimerization as well as in RNA binding (Lu et al., 1994; Qian et al., 1994), does not inhibit splicing (data not shown). The less efficient inhibition of splicing caused by the 38/41 mutant protein, as compared to the wild-type NS1A protein, can be attributed to the less efficient dimerization of the 38/41 mutant protein (see Fig. 1A) and/or to a small amount of inhibition caused by the RNA-binding domain of the wild-type NS1A protein, that is, via its binding to U6 snRNA (Lu et al., 1994; Qiu et al., 1995). Nonetheless, these results indicate that the effector domain alone is sufficient for the inhibition of the splicing of a single intron pre-mRNA in vivo.

To determine whether the NS1A protein preferentially inhibits either $3^{\prime}$-end processing or splicing, we carried out a cotransfection experiment in which we simultaneously analyzed the $3^{\prime}$-end processing and the splicing of the $\beta$-globin pre-mRNA using the long RNA probe shown in Figure 3A. In the absence of the NS1A protein, more than $95 \%$ of the single-intron $\beta$-globin pre-mRNA is both processed at the $3^{\prime}$ end and spliced (Fig. 3C, lane 1). In the presence of the wild-type NS1A protein, the predominant RNA species is the unprocessed $\beta$-globin pre-mRNA target (Fig. 3C, lane 2), indicating that in this experiment, the wild-type NS1A protein almost completely inhibits both the 3 '-end processing and the splicing of the single-intron $\beta$-globin pre-mRNA. Under these conditions, the 38/41 mutant protein also inhibits both the $3^{\prime}$-end processing and the splicing of the $\beta$-globin pre-mRNA, though not as effectively (Fig. 3C, lane 3). Of the three RNA species that have undergone one or both processing steps, the predominant RNA is fully processed mRNA, that is, the RNA species that has undergone both $3^{\prime}$-end processing and splicing. This indicates that $3^{\prime}$-end processing and splicing are inhibited to similar extents by the $38 / 41$ mutant protein. Furthermore, the observation that similar low amounts of the partially processed RNA species (the $b$ and c species in Fig. $3 \mathrm{C}$ ) are produced in the presence of either the wild-type or the $38 / 41 \mathrm{NS} 1 \mathrm{~A}$ protein suggests that the RNA-binding domain in the wild-type protein does not contribute significantly to the inhibition of splicing.

\section{The binding of the 30-kDa CPSF protein by the effector domain of the NS1A protein is required for the inhibition of the splicing of a single intron pre-mRNA in vivo}

One hypothesis that fits the above results is that the inhibition of the splicing of a single intron pre-mRNA is indirect and results from the inhibition of the $3^{\prime}$-end processing of the pre-mRNA by the effector domain of the NS1A protein. If this is the case, then it would be predicted that a mutant NS1A protein that lacks the effector domain binding site for the 30-kDa CPSF protein and/or the PABII protein would not inhibit this splicing.

Accordingly, we mapped the binding sites of these two cellular proteins on the effector domain of the NS1A protein. In the first set of experiments, we deleted various lengths of the C-terminus of the effector domain and measured the ability of these deletion mutants to bind to either GST-PABII or GST-30-kDa CPSF (Fig. 4, compare lanes $2-5$ to lane 1). The NS1A protein containing either the N-terminal 215 or 223 amino acids efficiently binds to the $30-\mathrm{kDa}$ CPSF protein, but binds poorly, if at all, to the PABII protein (Fig. 4, lanes 4 and 5), indicating that the $23 \mathrm{C}$-terminal amino acids (amino acids 223-237) of the NS1A protein are required for the binding of $\mathrm{PABII}$, but not for the binding of $30-\mathrm{kDa}$ CPSF. Because the NS1A protein containing the $\mathrm{N}$-terminal 180 amino acids does not bind to the $30-\mathrm{kDa}$ protein (Fig. 4, lane 3), but the N-terminal 215 amino acid sequence does bind (lane 4), the NS1A amino acid sequence from 180 to 215 is likely required for the binding of the $30-\mathrm{kDa}$ CPSF. This conclusion was confirmed by making two internal deletions (Fig. 4, lanes 6 and 7). In particular, deletion of amino acids 175-210 eliminated essentially all binding of the NS1A protein to $30-\mathrm{kDa}$ CPSF, but had little or no effect on PABIl binding (Fig. 4, lane 7). We conclude that the 223-237 amino acid sequence of the NS1A protein is required for the binding of PABII, and that the 175-210 NS1A amino acid sequence is required for binding the $30-\mathrm{kDa}$ subunit of CPSF.

As expected, deletion of the 30-kDa CPSF binding site renders the NS1A protein inactive in the inhibition of the $3^{\prime}$-end cleavage of the single-intron $\beta$-globin premRNA (Fig. 5A, compare lanes 4 and 5 to lane 1 ), whereas deletion of the PABII-binding site does not reduce the ability of the NS1A protein to inhibit 3 '-end cleavage (Fig. 5A, lanes 2 and 3 ). In addition, as shown in Figure $5 \mathrm{~B}$, deletion of the $30-\mathrm{kDa}$ CPSF binding site renders the NS1A protein inactive in the inhibition of the splicing of the single-intron $\beta$-globin pre-mRNA, despite the presence of a wild-type RNA-binding domain in this mutant NS1A protein (Fig. 5B, compare lanes 4 and 5 to lane 1). In contrast, deletion of the PABIIbinding site does not affect the splicing inhibitory activity of the NS1A protein (Fig. 5B, compare lanes 2 and $3)$. These results strongly suggest that the inhibition of the splicing of a single intron pre-mRNA by the NS1A protein occurs only when it binds and inhibits the function of the 30-kDa CPSF protein in $3^{\prime}$-end processing.

To identify the specific amino acids in the 175-210 region of the NS1A protein that are required for $30-\mathrm{kDa}$ 
A
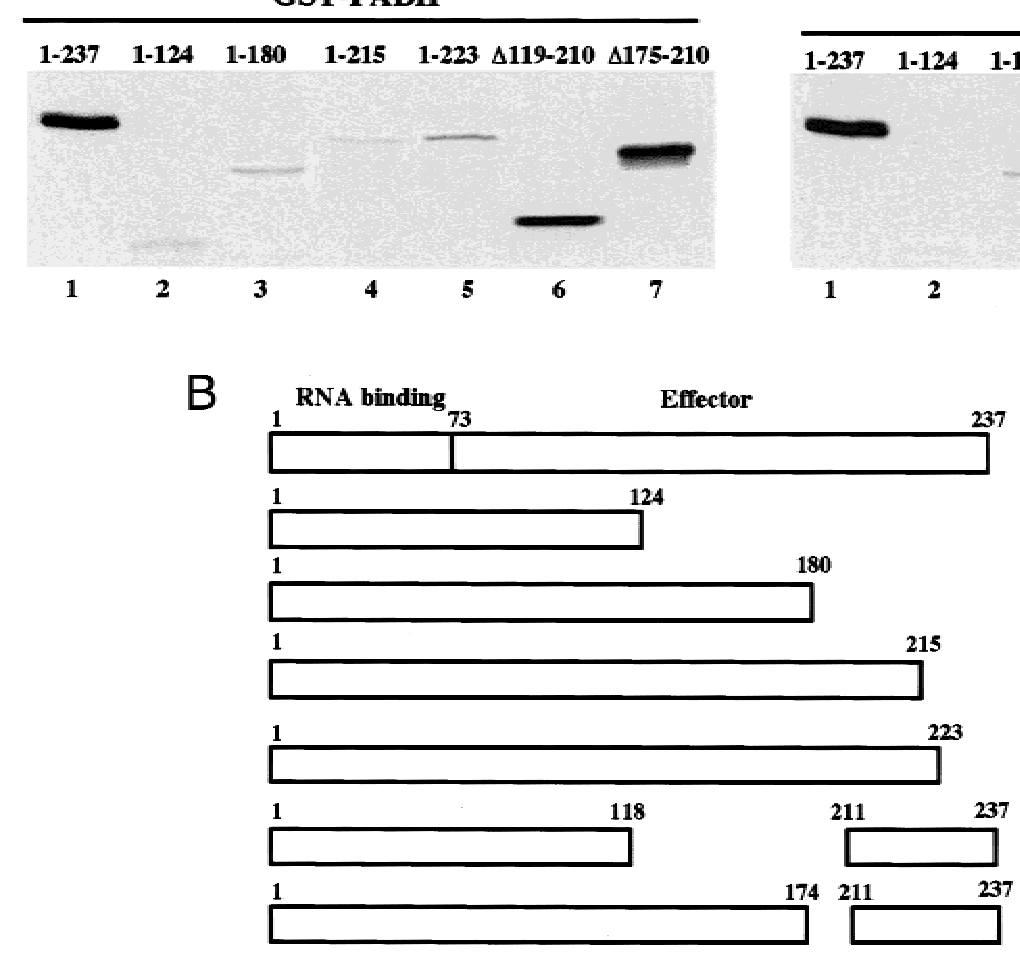

GST-30kD CPSF

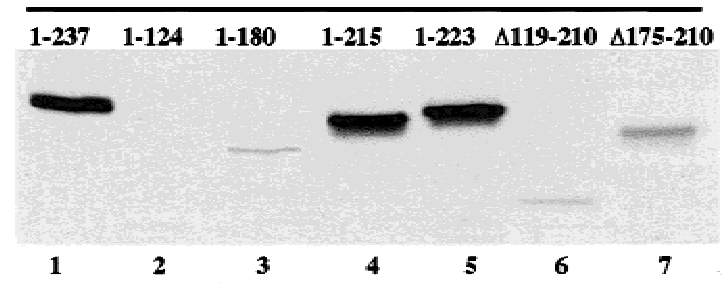

PABII 30kD CPSF

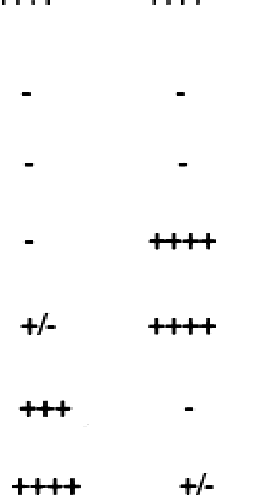

FIGURE 4. Identification of the binding site for PABII and 30-kDa CPSF on the NS1A protein. A: Binding assay. The GST-PABII protein $\left(2 \mu \mathrm{g}\right.$; left panel) or the GST-30-kDa CPSF protein $\left(2 \mu \mathrm{g}\right.$; right panel) was incubated with $10^{4} \mathrm{cpm}$ of ${ }^{35}$ S-labeled full-length NS1A protein (lane 1), or the indicated fragment of the NS1A protein (lanes 2-7) in the presence of $20 \mu \mathrm{L}$ of glutathione-Sepharose 4B beads. The same amount of each radiolabeled NS1A fragment was added to the binding assay. The labeled proteins eluted from the GST fusion protein on the beads were analyzed by electrophoresis on a $12 \%$ SDS-polyacrylamide gel. B: Schematic diagram of the fragments of the NS1A protein that were used in the binding assay, and a summary of the binding results.

CPSF binding, we introduced two amino acid substitutions at several locations in this region (Fig. 6). Of the three substitution mutants, only one, the substitution of AS for the EW at positions 185 and 186 of the NS1A protein (M (mutant) 186), specifically eliminates the binding of the NS1A protein to the 30-kDa CPSF protein, but has no effect on PABII protein binding. We conclude that the EW at positions 185 and 186 is specifically required for the binding of $30-\mathrm{kDa}$ CPSF protein. Therefore any loss of function of the M186 mutant is most likely attributable to the absence of $30-k D a$ CPSF binding.

Transfection experiments showed that the M186 NS1A protein does not inhibit either 3 '-end cleavage (Fig. 7A) or splicing (Fig. 7B) of the single-intron $\beta$-globin pre-mRNA, despite the presence of a wildtype RNA-binding domain in this mutant NS1A protein. Similar amounts of the M186 and wild-type NS1A proteins are made in the transfected cells (Fig. 7C), and the M186 mutant protein, like the wild-type protein, is localized in the nucleus (Fig. 7D). The intranuclear distribution of the M186 protein does differ from that of the wild-type protein, which may be attributable to the loss of CPSF-binding activity (see Discussion). These results demonstrate that inhibition of the function of the CPSF 3 '-end-processing factor is required for the NS1A protein-mediated inhibition of the splicing of a single-intron pre-mRNA.

\section{DISCUSSION}

\section{$3^{\prime}$-end processing is required for the splicing of single-intron cellular pre-mRNAs in vivo}

In vitro experiments in which pre-mRNA substrates were added to nuclear extracts that are active in both splicing and $3^{\prime}$-end processing have shown that the splicing of a single-intron pre-mRNA in vitro requires $3^{\prime}$-end processing (Niwa \& Berget, 1991; Berget, 1995; Vagner et al., 2000). In addition, mutation of the AAUAAA sequence in a multi-intron pre-mRNA inhibits the in vitro splicing of the $3^{\prime}$ terminal intron, but not the splicing of distal introns, particularly in the presence of a low concentration of magnesium (Niwa \& Berget, 1991). Two factors, poly (A) polymerase (PAP) and $\mathrm{U}^{2} \mathrm{AF}^{65}$, have been implicated in the coupling of $3^{\prime}$-end processing and the splicing of the $3^{\prime}$ terminal intron in vitro (Gunderson et al., 1997; Vagner et al., 2000). When PAP, which catalyzes the synthesis of the $3^{\prime}$ poly $(A)$ tails, is 

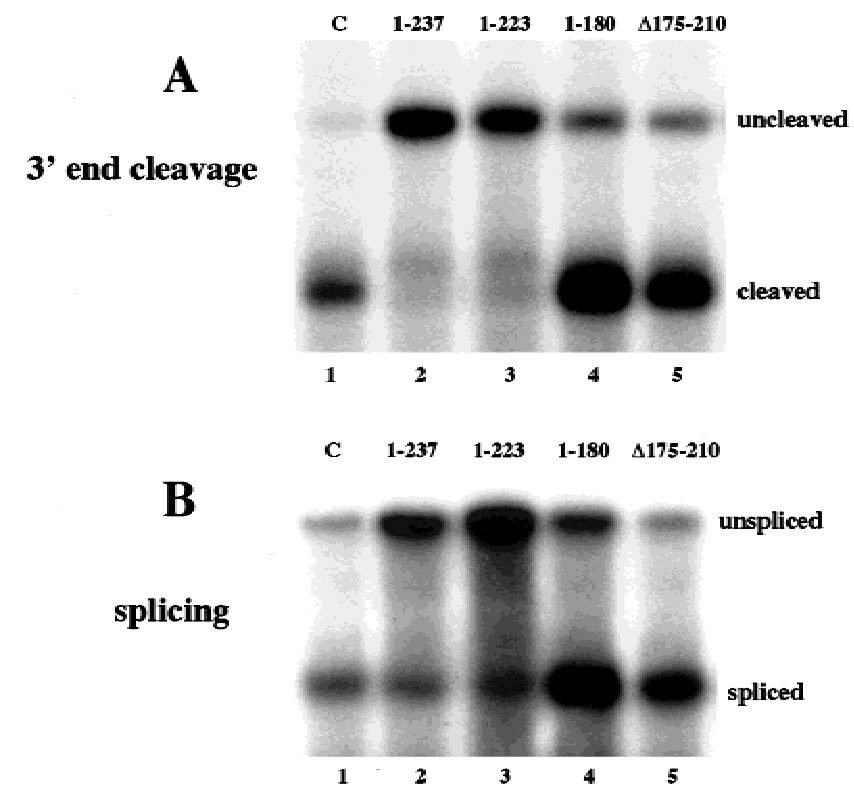

FIGURE 5. Deletion of the $30-\mathrm{kDa}$ CPSF binding site, but not of the PABII binding site, renders the NS1A protein inactive in the inhibition of both the $3^{\prime}$-end cleavage $(\mathbf{A})$ and the splicing $(\mathbf{B})$ of the singleintron $\beta$-globin pre-mRNA. We cotransfected 293 cells with a pBC12 plasmid encoding the $\beta$-globin pre-mRNA with a single intron and a pBC12 plasmid encoding either the wild-type NS1A protein (lane 2) or an NS1A protein containing the indicated deletion (lanes 3-5). Control $(\mathrm{C}$, lane 1$)$ : the $\mathrm{pBC} 12$ plasmid encodes an NS1A reading frame containing two stop codons. The cellular RNA was subjected to a RNase protection assay using the $3^{\prime}$-end processing probe $(\mathbf{A})$ or the splicing probe $(\mathbf{B})$. anchored to a pre-mRNA about 50 nt downstream of the intron $3^{\prime}$ splice site, it interacts with $\mathrm{U}_{2} \mathrm{AF}^{65}$ that is bound to the pyrimidine tract adjacent to the $3^{\prime}$ splice site, and, as a result, the binding of $\mathrm{U}^{2} \mathrm{AF}^{65}$ as well as the splicing of the $3^{\prime}$ terminal intron is enhanced (Vagner et al., 2000). Based on this result, it was postulated that a $3^{\prime}$ poly (A) site functions essentially as a splicing enhancer, with splicing enhancement mediated via specific interactions between PAP and U2AF65 (Vagner et al., 2000).

In contrast, previous experiments failed to show that $3^{\prime}$-end processing is required for the splicing of a singleintron pre-mRNA in vivo. In fact, mutational inactivation of the $3^{\prime} \operatorname{poly}(A)$ site that is normally used for $3^{\prime}$-end processing of a mammalian pre-mRNA did not inhibit the splicing of the $3^{\prime}$ terminal intron in vivo because cryptic 3' poly(A) sites were activated (Nesic et al., 1995). In the present study, we have used a global inhibition of $3^{\prime}$-end processing to establish that $3^{\prime}$-end processing is required for the splicing of a single intron pre-mRNA. We used the effector domain of the influenza virus NS1A protein, which inhibits the $3^{\prime}$-end processing machinery by binding $30-\mathrm{kDa}$ CPSF and PABII molecules (Nemeroff et al., 1998; Chen et al., 1999). We show that the NS1A effector domain alone is necessary and sufficient for inhibition of not only the $3^{\prime}$ end processing but also the splicing of single-intron pre-mRNAs in vivo. In addition, we demonstrate that
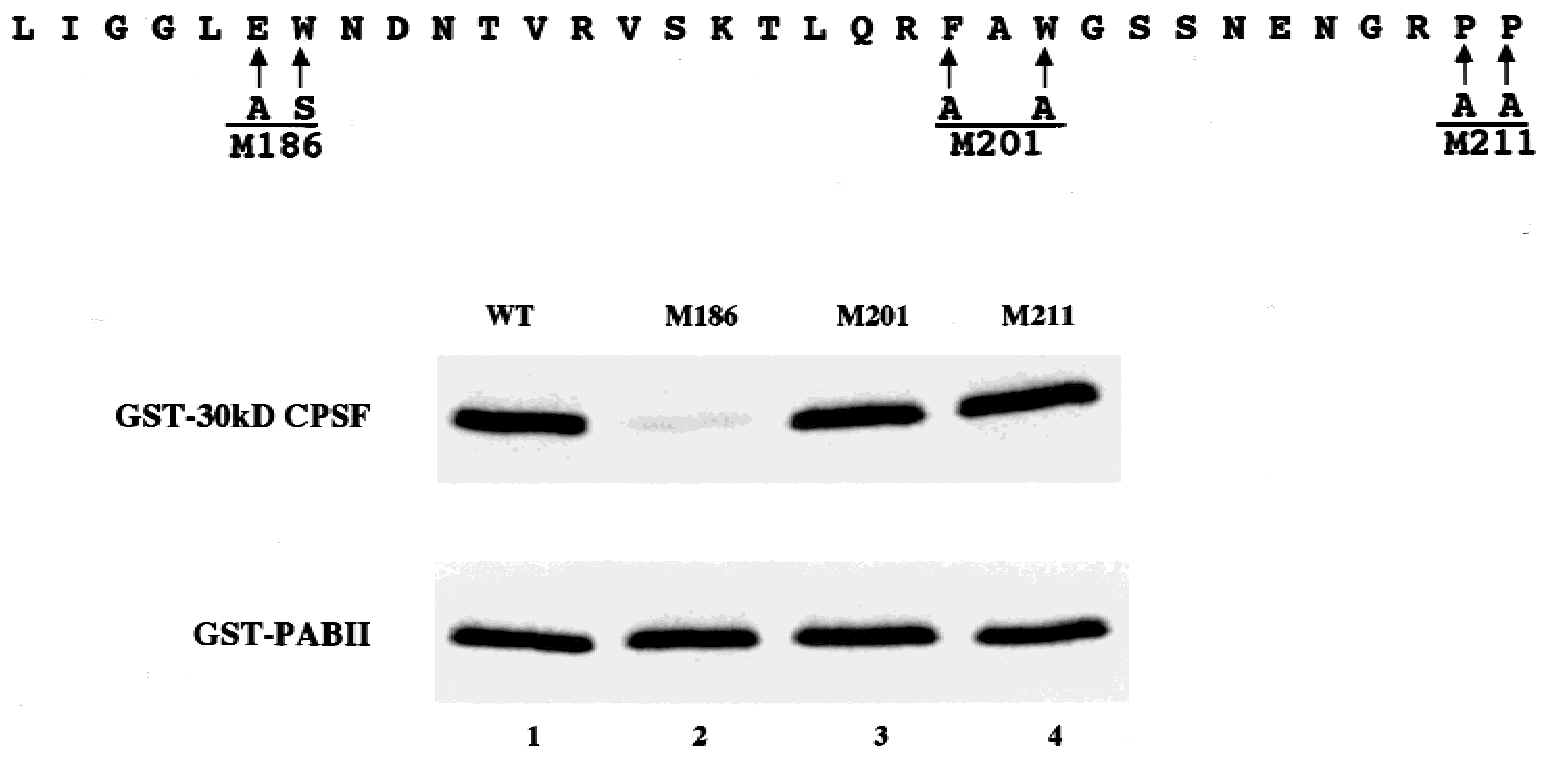

FIGURE 6. Identification of the specific amino acids in the 180-212 region of the NS1A protein that are required for the binding of the $30-\mathrm{kDa}$ CPSF protein. Top: The three sets of mutations introduced into this region of the NS1A protein. Bottom: The binding of the three mutant proteins to 30-kDa CPSF and PABII. The GST-30-kDa CPSF protein $(2 \mu \mathrm{g})$ or the GST-PABII protein $(2 \mu \mathrm{g})$ was incubated with $10^{4} \mathrm{cpm}$ of ${ }^{35} \mathrm{~S}$-labeled wild-type (WT) NS1A protein (lane 1), or the indicated NS1A mutant protein (lanes 2-4) in the presence of $20 \mu \mathrm{L}$ of glutathione-Sepharose 4B beads, and the amount of the labeled NS1A that was bound to, and eluted from, the GST fusion protein on the beads was determined by electrophoresis on a $12 \%$ SDS-polyacrylamide gel. 


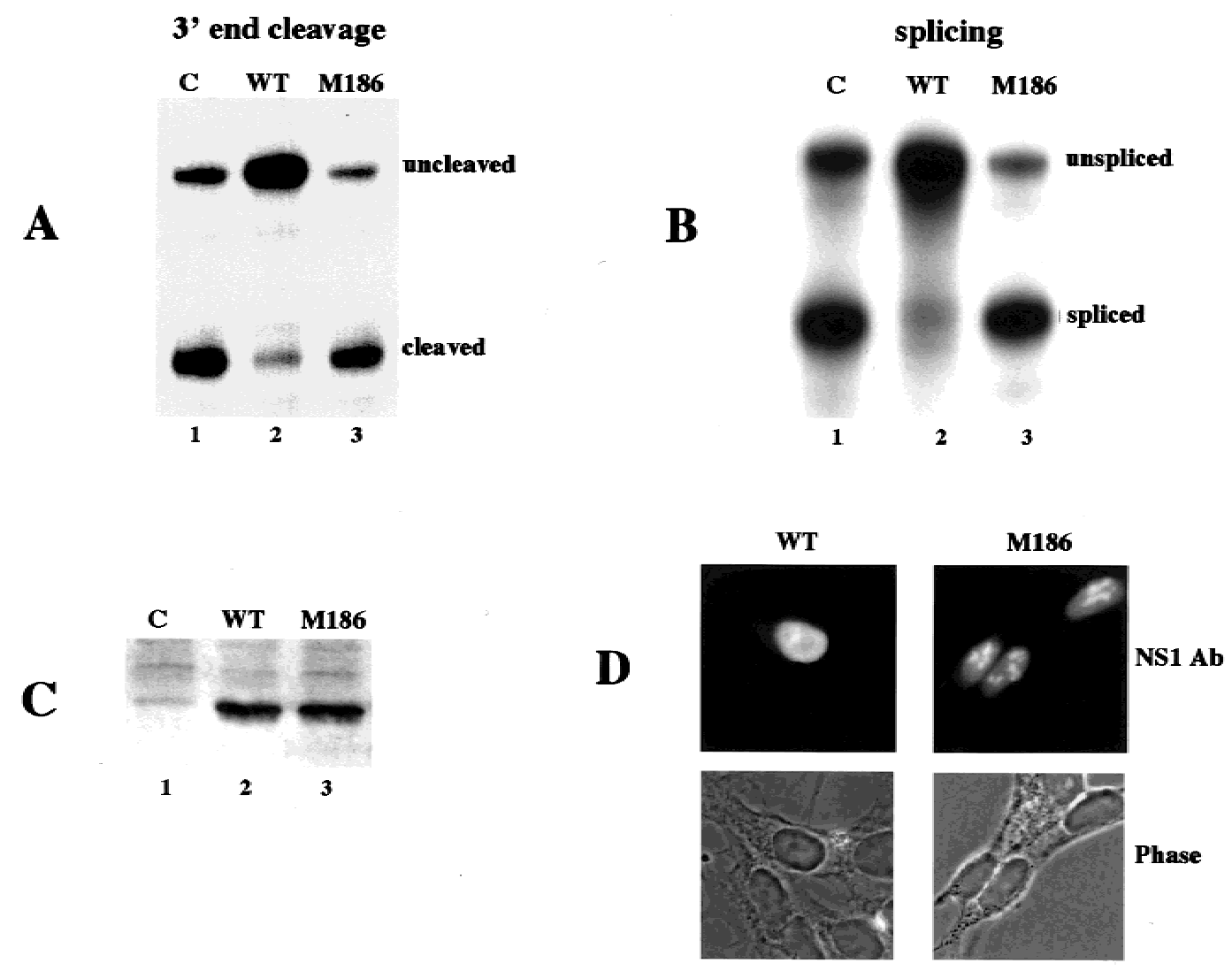

FIGURE 7. The M186 mutant NS1A protein does not inhibit either $3^{\prime}$-end cleavage or splicing of the single-intron $\beta$-globin pre-mRNA. A: $3^{\prime}$-end cleavage. We cotransfected 293 cells with a pBC12 plasmid encoding the $\beta$-globin pre-mRNA with a single intron and a pBC12 plasmid encoding either the wild-type (WT) NS1A protein (lane 2) or an NS1A protein containing the M186 mutation (lane 3). Control (C, lane 1): the pBC12 plasmid encodes an NS1A reading frame containing two stop codons. The cellular RNA was subjected to a RNase protection assay using the 3 '-end-processing probe. B: Splicing. The cellular RNA from these transfected cells was subjected to a RNase protection assay using the splicing probe. C: Western analysis of the NS1A protein synthesized in the 293 cells transfected with the plasmid encoding the wild-type (WT) or M186 mutant NS1A protein. The procedure used is described in Nemeroff et al. (1998). D: The nuclear localization of the wild-type (WT) and M186 mutant proteins in transfected cells. Top panels: indirect immunofluorescence using NS1A antiserum. Bottom panels: the corresponding phase-contrast pictures.

the inhibition of splicing occurs only when the effector domain of the NS1A protein binds the 30-kDa CPSF protein and as a result inhibits its function in $3^{\prime}$-end processing. In contrast, the binding of PABII to the NS1A effector domain does not inhibit splicing. Decisive evidence was obtained using the M186 mutant NS1A protein in which only two amino acids (E185 and W186) are replaced with alanine and serine, respectively. This mutation specifically eliminates the binding of the 30-kDa CPSF protein, but not the binding of the PABII protein, and results in the concomitant loss of two in vivo functions, inhibition of 3 '-end cleavage and splicing of a single-intron pre-mRNA. Hence, our results demonstrate that CPSF molecules that function in $3^{\prime}$ end processing are also required for the splicing of a single-intron pre-mRNA in vivo and therefore implicate CPSF in the coupling of splicing and $3^{\prime}$-end processing.

As proposed for the coupling of $3^{\prime}$-end processing and splicing in vitro (Vagner et al., 2000), CPSF may be required for the splicing of a $3^{\prime}$ terminal intron because it initiates the establishment of the cleavage/polyadenylation complex at the AAUAAA sequence of the pre-mRNA. The PAP in this complex could then enhance splicing by interacting with $\mathrm{U}^{2} \mathrm{AF}^{65}$ and hence stabilizing its binding to the polypyrimidine tract adjacent to the $3^{\prime}$ splice site. In addition, another mechanism may operate in vivo: the formation of a functional "pol II transcriptosome" may be adversely affected by the binding of the NS1A protein to CPSF, one of the first RNA processing factors that bind to the CTD of RNA polymerase II during the initiation of transcription (Dantonel et al., 1997). For example, the binding of the NS1A protein to CPSF may block CPSF from binding to the CTD of RNA polymerase II. Alternatively, the NS1A protein may not deter the binding of CPSF to the CTD, but instead may remain complexed to the bound CPSF molecules. The latter possibility is consistent with our observation that the intranuclear distribution of the M186 mutant NS1A protein, which does not bind the $30-k D a$ CPSF protein, differs from that of the 
wild-type NS1A protein: Unlike the wild-type NS1A protein, the M186 mutant NS1A protein is not uniformly distributed in the nucleus, but rather is concentrated in discrete spots in the nucleus (Fig. 7D). Our previous results showed that 30-kDa CPSF and the wild-type NS1A protein have an overlapping and relatively uniform distribution in the nucleus (Chen et al., 1999), suggesting that wild-type NS1A protein, and not the M186 mutant NS1A protein, may be associated with CPSF molecules that are in transcriptosomes. Either of the postulated NS1A protein-mediated effects on transcriptosome formation could also result in the lack of binding of at least some splicing factors to the CTD. As a consequence, the splicing of not only the $3^{\prime}$ terminal intron but also of upstream introns may be inhibited by the NS1A effector domain. Experiments to test this possibility are in progress.

Previous in vitro experiments implicated the RNAbinding domain in the inhibition of splicing: This domain binds to a specific stem-bulge in U6 snRNA in vitro (Qiu et al., 1995), and such binding is sufficient for the inhibition of the in vitro splicing of pre-mRNAs that lack a 3'-end processing site (Lu et al., 1994; Qu et al., 1995). In contrast, the results presented here indicate that in vivo, the RNA-binding domain of the NS1A protein has little or no effect on the splicing of a singleintron pre-mRNA that is transcribed by the cellular RNA polymerase II, and that the effector domain mediates the inhibition of splicing via the binding of the $30-\mathrm{kDa}$ subunit of CPSF. Thus, the 38/41 mutant NS1A protein, which contains a wild-type effector domain but lacks a functional RNA-binding domain, inhibits such splicing almost as well as the wild-type NS1A protein. The small reduction in this activity is accompanied by a similar small reduction in the ability to inhibit 3 '-end processing, indicating that the $38 / 41$ mutation probably causes a small reduction in several activities of the NS1A protein. This reduction in overall activity can be attributed to the slightly lower dimerization activity of the $38 / 41$ mutant protein. We interpret these results to indicate that functional transcriptosomes are not formed in vivo in the presence of a wild-type NS1A effector domain. Consequently spliceosomes containing U6 snRNA would not be assembled, thereby obviating any effect of the RNA-binding domain.

In addition, we show that even when CPSF is functional, the RNA-binding domain of the NS1A protein does not play a significant role in inhibiting splicing in vivo: the M186 mutant NS1A protein, which does not inhibit CPSF function, does not inhibit the splicing of a single-intron pre-mRNA even though this NS1A protein has a wild-type RNA-binding domain. This result indicates that the NS1A RNA-binding domain does not access U6 snRNA during coupled transcription-RNA processing mediated by the pol II transcriptosome. Under these conditions the NS1A RNA-binding domain apparently cannot effectively compete with cellular pro- teins for U6 snRNA. The NS1A RNA-binding domain has a low affinity for its RNA targets (Wang et al., 1999; C. Chien, J.M. Aramini, Y. Xu, P.V. Sahasrabudhe, R. Xiao, R.M. Krug, and G.T. Montelione, in prep.), and both U6 snRNA binding and the inhibition of in vitro splicing require relatively high concentrations of the NS1A protein (approximately $1 \mu \mathrm{M}$; Lu et al., 1994; Qiu et al., 1995).

\section{Implications for the splicing of viral mRNAs in influenza virus-infected cells}

Inhibition of pre-mRNA splicing that is mediated via the inhibition of $3^{\prime}$-end processing by the effector domain of the NS1A protein would not affect the splicing of the influenza virus M1 and NS1 mRNAs, because the cellular $3^{\prime}$-end-processing machinery is not used for producing the $3^{\prime}$ poly $(A)$ ends of viral mRNAs. Instead, the poly $(A)$ tails on influenza viral mRNAs are synthesized by the virus-encoded transcriptase, which reiteratively copies a short stretch of $U$ residues in the virion RNA template (Robertson et al., 1981; Krug et al., 1989; Poon et al., 1999). Consequently, the effector domain of the viral NS1A protein selectively inhibits cellular, and not viral, $3^{\prime}$-end processing and splicing because it targets the $3^{\prime}$-end-processing system that is used only by the cell, and not by the virus.

The fact that the influenza virus M1 and NS1 mRNAs are spliced by the cellular splicing machinery indicates that splicing can be uncoupled from transcription by the cellular RNA polymerase II. However, the splicing of these two single intron viral mRNAs is inefficient: The steady-state amount of the spliced mRNA products is only about $10 \%$ of that of the unspliced mRNA precursors (Lamb et al., 1980, 1981). Incomplete splicing is necessary because both the spliced and unspliced mRNAs are exported to the cytoplasm and are translated into virus-specific proteins (reviewed in Krug et al., 1989). The results presented here provide an explanation for the inefficient splicing of these two single-intron influenza viral mRNAs: this splicing is not coupled to CPSF-dependent $3^{\prime}$-end formation. In addition, splicing which is uncoupled from polymerase II transcription may be intrinsically inefficient. Finally, because the export of the unspliced NS1 and M1 mRNAs in influenza virus-infected cells is rapid (Alonso-Caplen \& Krug, 1991), some mechanism may efficiently remove these viral mRNAs from the cellular splicing machinery.

\section{MATERIALS AND METHODS}

\section{Plasmids}

The wild-type NS1A gene contains a mutated 3 ' splice site to block the production of spliced NS2A mRNA (Qian et al., 1994). Oligonucleotide-directed mutagenesis was used to introduce the indicated alanine or serine substitutions into the 
NS1A protein, and PCR was used to generate the indicated deletions. The wild-type and mutant NS1A sequences were cloned into the pBC12 vector for transfection experiments, and were cloned into the pGEX-3X vector for the preparation of GST fusion proteins. The plasmid that was used to express a target pre-mRNA in transfection experiments was a pBC12 plasmid containing a human $\beta$-globin minigene with a single intron, and the rat preproinsulin II gene poly $(\mathrm{A})$ signal.

\section{Dimerization assay}

${ }^{35}$ S-labeled full-length NS1A protein $(10 \mu \mathrm{L})$ synthesized in vitro was combined with the indicated purified GST-NS1A fusion protein $(5 \mu \mathrm{g}), 20 \mu \mathrm{L}$ of glutathione-Sepharose 4B beads, and $400 \mu \mathrm{L}$ of IPP 150 buffer (10 mM Tris- $\mathrm{HCl}, \mathrm{pH} 8.0$, $150 \mathrm{mM} \mathrm{NaCl}$, and $0.1 \%$ Nonidet P-40) in 1.5-mL microfuge tubes. After incubation at $4{ }^{\circ} \mathrm{C}$ for $1.5 \mathrm{~h}$, the beads were washed as described previously (Wang et al., 1999), and were then resuspended in gel loading buffer containing $5 \%$ (v/v) 2-mercaptoethanol and heated at $95^{\circ} \mathrm{C}$ for $2 \mathrm{~min}$. The resulting eluate was analyzed by gel electrophoresis on a $14 \%$ SDS-polyacrylamide gel. The ${ }^{35}$ S-labeled NS1A protein was detected by fluorography of the SDS-polyacrylamide gel.

\section{RNA-binding assay}

The GST portion of the GST fusion proteins used in the RNA-binding assay was cleaved using the protease factor Xa. ${ }^{32} \mathrm{P}$-labeled U6 snRNA was prepared as described previously (Qiu et al., 1995). The indicated NS1A protein was mixed with the labeled U6 snRNA $(10,000 \mathrm{cpm}, 1 \mathrm{nM})$ in an RNA-binding solution (Wang et al., 1999) in a total volume of $20 \mu \mathrm{L}$, and the mixture was incubated on ice for $30 \mathrm{~min}$. The RNA-protein complexes were resolved from free RNA by nondenaturing electrophoresis on a $6 \%$ polyacrylamide gel for $3 \mathrm{~h}$ at $4{ }^{\circ} \mathrm{C}$ at $150 \mathrm{~V}$ using $45 \mathrm{mM}$ Tris-borate, $1 \mathrm{mM}$ EDTA as running buffer.

\section{Assays for $3^{\prime}$-end cleavage and splicing of pre-mRNAs in vivo}

We cotransfected 293 cells with the pBC12 plasmid containing a human $\beta$-globin minigene and one of the NS1Acontaining $\mathrm{pBC} 12$ plasmids using calcium phosphate (Qian et al., 1994). Transfected cells were collected at $40 \mathrm{~h}$ posttransfection. An aliquot of the total cell RNA was assayed by $R$ Nase protection using the indicated uniformly labeled RNA probe. The DNA used for the indicated probe was inserted into the BamH1 site of the pGEM plasmid, which was then linearized with Pvul. The inserted DNA was copied into RNA using SP6 RNA polymerase and $\left(\alpha-{ }^{32} \mathrm{P}\right)$ UTP. After annealing the labeled RNA probe to the cellular RNA sample, followed by digestion with RNAse $A$ and phenol extraction, the protected RNA fragments were resolved by electrophoresis on a urea-polyacrylamide $(7 \%)$ gel.

\section{Glutathione sepharose affinity selection}

The GST-PABII or GST-30-kDa CPSF fusion protein, which was expressed and purified as previously described (Chen et al., 1999), was combined with the indicated ${ }^{35}$ S-labeled NS1A protein sequence synthesized in vitro, and was subjected to glutathione sepharose affinity selection as previously described (Nemeroff et al., 1995). To prepare the labeled NS1A protein sequence, the DNA encoding this sequence was cloned into pGEM1 and translated using a Promega TnT Coupled Transcription/Translation kit in the presence of ${ }^{35}$ S-methionine.

\section{Indirect immunofluorescence}

We transfected 293 cells, which were grown on glass coverslips, with a pBC12 plasmid encoding either wild-type NS1A or the M186 mutant NS1A protein. Cells were analyzed by indirect immunofluorescence as described previously, using monoclonal mouse antibodies against the NS1A protein (kindly provided by Jonathan Yewdell) and FITC-conjugated goat anti-mouse antibody (Chen et al., 1999).

\section{ACKNOWLEDGMENT}

This investigation was supported by National Institutes of Health Grant Al11772 to R.M.K.

Received February 21, 2001; returned for revision

March 14, 2001; revised manuscript received

March 20, 2001

\section{REFERENCES}

Alonso-Caplen FV, Krug RM. 1991. Regulation of the extent of splicing of influenza virus NS1 mRNA: Role of the rate of splicing and of the nucleocytoplasmic transport of NS1 mRNA. Mol Cell Biol 11:1092-1098.

Barabino SML, Huebner W, Jenny A, Minvielle-Sebastia L, Keller W. 1997. The $30-\mathrm{kD}$ subunit of mammalian cleavage and polyadenylation specificity factor and its yeast homolog are RNA-binding zinc finger proteins. Genes \& Dev 11:1703-1716.

Bentley D. 1999. Coupling RNA polymerase II transcription with premRNA processing. Curr Opin Cell Biol 11:347-351.

Berget SM. 1995. Exon recognition in vertebrate splicing. J Biol Chem 270:2411-2414.

Chen Z, Li Y, Krug RM. 1999. Influenza A virus NS1 protein targets poly(A)-binding protein II of the cellular $3^{\prime}$ end processing machinery. EMBO J 18:2273-2283.

Colgan DF, Manley JL. 1997. Mechanism and regulation of mRNA polyadenylation. Genes \& Dev 11:2755-2766.

Dantonel JC, Murthy KG, Manley JL, Tora L. 1997. Transcription factor TFIID recruits factor CPSF for formation of $3^{\prime}$ end of mRNA. Nature 389:399-402.

Du L, Warren SL. 1997. A functional interaction between the carboxyterminal domain of RNA polymerase II and pre-mRNA splicing. $J$ Cell Biol 136:5-18.

Dye MJ, Proudfoot NJ. 1999. Terminal exon definition occurs cotranscriptionally and promotes termination of RNA polymerase II. Mol Cell 3:371-378.

Fortes P, Belos A, Ortin J. 1994. Influenza virus NS1 protein inhibits pre-mRNA splicing and blocks mRNA nucleocytoplasmic transport. EMBO J 13:704-712.

Gunderson SI, Vagner S, Polycarpou-Schwarz M, Mattaj IW. 1997. Involvement of the carboxy terminus of vertebrate poly $(A)$ polymerase in U1A autoregulation and in the coupling of splicing and polyadenylation. Genes \& Dev 11:761-773.

Hirose Y, Manley JL. 1998. RNA polymerase II is an essential mRNA polyadenylation factor. Nature 395:93-96.

Hirose Y, Manley JL. 2000. RNA polymerase II and the integration of nuclear events. Genes \& Dev 14:1415-1429. 
Hirose Y, Tacke R, Manley JL. 1999. Phosphorylated RNA polymerase II stimulates pre-mRNA splicing. Genes \& Dev 13:1234-1239.

Jenny A, Hauri H-P, Keller W. 1994. Characterization of cleavage and polyadenylation specificity factor and cloning of its 100-kilodalton subunit. Mol Cell Biol 14:8183-8190.

Keller W, Bienroth S, Lang KM, Christofori G. 1991. Cleavage and polyadenylation factor (CPF) specifically interacts with the premRNA 3'processing signal AAUAAA. EMBO J 10:4241-4249.

Krug RM, Alonso-Caplen FV, Julkunen I, Katze M. 1989. Expression and replication of the influenza virus genome. In: Krug RM, ed. The influenza viruses. New York and London: Plenum Press. pp 89-152.

Lamb RA, Choppin PW, Chanock RM, Lai C-J. 1980. Mapping of the two overlapping genes for polypeptides NS1 and NS2 on RNA segment 8 of influenza virus genome. Proc Natl Acad Sci USA 78:1857-1861.

Lamb RA, Lai C-J, Choppin PW. 1981. Sequences of mRNAs derived from genome RNA segment 7 of influenza virus: Colinear and interrupted mRNAs code for overlapping proteins. Proc Natl Acad Sci USA 78:4170-4175.

Lu Y, Qian X-Y, Krug RM. 1994. The influenza virus NS1 protein: A novel inhibitor of pre-mRNA splicing. Genes \& Dev 8:1817-1828.

McCracken S, Fong N, Yankulov K, Ballantyne S, Pan G, Greenblatt J, Patterson SD, Wickens M, Bentley DL. 1997. The C-terminal domain of RNA polymerase II couples mRNA processing to transcription. Nature 385:357-361.

Minvielle-Sebastia L, Keller W. 1999. mRNA polyadenylation and its coupling to other RNA processing reactions and to transcription. Curr Opin Cell Biol 11:352-357.

Misteli T, Spector DL. 1999. RNA polymerase II targets pre-mRNA splicing factors to transcription sites in vivo. Mol Cell 3:697-705.

Murthy KGK, Manley JL. 1992. Characterization of the multisubunit cleavage-polyadenylation specificity factor from calf thymus. $J$ Biol Chem 267:14804-14811.

Nemeroff M, Barabino SML, Keller W, Krug RM. 1998. Influenza virus NS1 protein interacts with the $30 \mathrm{kD}$ subunit of cleavage and specificity factor and inhibits $3^{\prime}$ end formation of cellular pre-mRNAs. Mol Cell 1:991-1000.

Nemeroff ME, Qian X-Y, Krug RM. 1995. The influenza virus NS1 protein forms multimers in vitro and in vivo. Virol 212:422-428.

Nesic D, Maquat LE. 1994. Upstream introns influence the efficiency of final intron removal and RNA 3 '-end formation. Genes \& Dev 8:363-375
Nesic D, Zhang J, Maquat LE. 1995. Lack of an effect of the efficiency of RNA 3'-end formation on the efficiency of removal of either the final or the penultimate intron in intact cells. Mol Cell Biol 15:488-496.

Niwa M, Berget SM. 1991. Mutation of the AAUAAA polyadenylation signal depresses in vitro splicing of proximal but not distal introns. Genes \& Dev 5:2086-2095.

Niwa M, Rose SD, Berget SM. 1990. In vitro polyadenylation is stimulated by the presence of an upstream intron. Genes \& Dev 4:1552-1559.

Poon LL, Pritlove DC, Fodor E, Brownlee GG. 1999. Direct evidence that the poly $(A)$ tail of influenza A virus mRNA is synthesized by reiterative copying of a $U$ track in the virion RNA template. $J$ Virol 73:3473-3476.

Qian X-Y, Alonso-Caplen FV, Krug RM. 1994. Two functional domains of the influenza virus NS1 protein are required for regulation of nuclear export of mRNA. J Virol 68:2433-2441.

Qu Y, Krug RM. 1994. The influenza virus NS1 protein is a poly (A)binding protein that inhibits nuclear export of mRNAs containing poly (A). J Virol 68:2425-2432.

Qiu Y, Nemeroff ME, Krug RM. 1995. The influenza virus NS1 protein binds to a specific region in human U6 snRNA and inhibits U6-U2 and U6-U4 snRNA interactions during splicing. RNA 1:304-316.

Robertson JS, Schubert M, Lazzarini RA. 1981. Polyadenylation sites for influenza virus mRNA. J Virol 38:157-163.

Scott JM, Imperiale MJ. 1996. Reciprocal effects of splicing and polyadenylation on human immunodeficiency virus type 1 pre-mRNA processing. Virol 224:498-509.

Vagner S, Vagner C, Mattaj IW. 2000. The carboxyl terminus of vertebrate poly (A) polymerase interacts with U2AF 65 to couple $3^{\prime}$ end processing and splicing. Genes \& Dev 14:403-413.

Wahle E, Kuhn U. 1997. The mechanism of 3' cleavage and polyadenylation of eukaryotic pre-mRNA. Prog Nucleic Acid Res Mol Biol 57:41-71.

Wang W, Krug RM. 1996. The RNA-binding and effector domains are conserved to different extents among influenza $A$ and $B$ viruses. Virol 223:41-50.

Wang W, Riedel K, Lynch K, Chien C, Montelione GT, Krug RM. 1999. RNA-binding by the novel helical domain of the influenza virus NS1 protein requires its dimer structure and a small number of specific basic amino acids. RNA 5:195-205. 